\title{
Voz e autorrepresentação Mbya-guarani: uma análise do documentário Mokoi Tekoá Petei Jeguatá: duas aldeias, uma caminhada
}

\author{
Mauren Pavão Przybylski, Francisco Gabriel Rêgo \& Priscila Cardoso \\ de Oliveira Silva*
}

Resumo: Este artigo pretende analisar a voz, enquanto objeto de experiência e a autorrepresentação como elemento de legitimação de uma alteridade indígena. Para tanto, utilizaremos como corpus o documentário Mokoi Tekoá Petei Jeguatá: duas aldeias, uma caminhada. O texto é dividido em 3 momentos: 1) breves considerações acerca do conceito de voz, em que enfocaremos a voz guarani; 2) a dimensão oral da representação indígena: analisaremos de que forma o indígena se auto representa a partir do documentário; 3) do diálogo campo/antecampo no documentário procuraremos tecer algumas conclusões acerca da voz Mbya-guarani.

Palavras-chave: voz; auto representação; documentário; Mbya-Guarani.

Resumen: En este artículo se pretende analizar la voz como objeto de la experiencia y la auto-representación como elemento legitimador de una alteridad indígena. Para ello, utilizaremos como corpus el documental Mokoi Tekoá Petei Jeguatá: duas aldeias, uma caminhada. El texto se dividirá en 3 momentos: 1) Breves consideraciones sobre el concepto de voz, centrándonos en la voz guaraní; 2) Dimensión oral de la representación indígena: el caso del cine, analizando de qué modo el indígena se autorepresenta a partir del documental; 3) El diálogo campo/antecampo en el documental, procurando realizar algunas conclusiones acerca de la voz Mbya-guaraní.

Palabras clave: voz; autorepresentación; documental; Mbya-guaraní.

Abstract: This article analyzes the voice as an object of experience, and self-representation as a legitimating element of an indigenous otherness. Therefore, we will focus on the documentary Mokoi Tekoá Petei Jeguatá: duas aldeias, uma caminhada. The article is divided in three parts: 1) briefly discussion of the concept of voice, where we focus on Guarani voice; 2) the dimension of the oral voice of indigenous representation: we analyze how the voice is used in the representation; 3) the dialogue "campo/antecampo[field/out-of-field]" in the documentary, in which we will try to make some conclusions about the voice of Mbya-Guarani.

Keywords: voice; self representation; documentary; Mbya-Guarani.

* Mauren Pavão Przybylski: Pós-doutoranda. Universidade do Estado da Bahia UNEB / CAMPUS II, Programa de Pós-Graduação em Crítica Cultural, Bolsista PNPD/CAPES. 41925-010, Salvador, Brasil. E-mail: maurenpavao@gmail.com

Francisco Gabriel Rêgo: Mestrando. Universidade do Estado da Bahia - UNEB / CAMPUS II, Programa de Pós-Graduação em Crítica Cultural, Bolsista FAPESB. 41925-010, Salvador, Brasil. E-mail: francisco1gabriel@gmail.com

Priscila Cardoso de Oliveira Silva: Mestranda. Universidade do Estado da Bahia - UNEB / Campus II, Programa de Pós-Graduação em Crítica Cultural, Bolsista CAPES. 41925-010, Salvador, Brasil. Email: prioliveira1983@hotmail.com

Submissão do artigo: 30 de dezembro de 2015. Notificação de aceitação: 15 de fevereiro de 2016. 
Résumé: Cet article vise à analyser la voix comme objet d'expérience, et l'autoreprésentation comme un élément légitimant d'une altérité indigène. A cet effet, nous utiliserons le corpus documentaire Mokoi Tekoa Petei Jeguatá : soit deux villages, et une promenade. Le texte est divisé en 3 phases : 1) brèves considérations sir le concept de voix, en nous concentrant particulièrement sur la voix Guarani ; 2) la dimension orale de la représentation indigène : le cas du cinéma, dans lequel nous analysons comment l'indigène s'auto-représente dans le cinéma documentaire ; 3) à partir du dialogue champ / contrechamp dans le documentaire, on tentera de tirer des conclusions au sujet de la voix Mbya-Guarani.

Mots-clés: voix; auto-représentation; documentaire; Mbya-Guarani.

\section{Breves considerações: a voz na cultura guarani}

Das manifestações humanas, a voz é um objeto de experiência, situa-se no centro de um poder que está para além de qualquer conjunto de valores responsável pela fundação das culturas, sendo criadora de inúmeras formas de arte. Na cultura guarani, destaca-se, em especial, as peculiaridades inerentes a voz, atentando para o papel da oralidade nas manifestações indígenas. Nesses espaços, voz e memória aproximar-se-iam de modo quase indistinto. A memória cumpre a tarefa de profetizar as marcas do que havia se perdido e que irremediavelmente influi na linguagem e no tempo. ${ }^{1}$ Falar e transmitir a memória possibilitam compreender a voz como um produto complexo, resultado de interações biológicas, intelectuais, emocionais, sociais e espirituais, já que é o instrumento de trabalho e de comunicação mais difundido. ${ }^{2} \mathrm{Di}$ ante da complexidade ontológica da voz, entra-se no campo da poesia oral, já que esta circunscreve-se em um vasto e distinto conjunto de caracteres. Sua formulação ocorreria de forma rigorosa, promovendo indícios estruturais que se evidenciam em forte sentido de alteridade. Isso porque, nas poéticas orais é que se instauram as formas de sobrevivência, (re)emergência de um antes, de um ontem, pois muitas práticas da vida social são explicadas através dela. Percebem-se suas peculiaridades e influências dentro do cotidiano de toda e qualquer sociedade. Expressa crenças, valores, presentifica e reatualiza saberes.

A partir do descrito e da busca pelo sentido de alteridade, pretendemos observar a representação indígena no cinema, em especial no documentário

1. Memória, aqui, nos interessa quando relacionada ao conceito de voz, como lembrança, recordação e, por isso, não nos deteremos numa análise mais profunda do conceito.

2. FRANCO, Rosa Daniele, (2008) A voz: uma concepção fenomenológica. Dissertação de mestrado do Programa de Pós-Graduação em Música. Universidade Federal do Paraná, Curitiba. 
Mokoi Tekoá Petei Jeguatá: duas aldeias, uma caminhada (2008). ${ }^{3}$ Nosso intuito é o de apreender o papel da voz e, por conseguinte, das expressões tradicionais evidenciadas pela dimensão oral, como forma de se perceber o diálogo estabelecido entre os próprios índios e as expressões diferentes a ela.

Parte-se da autorrepresentação tendo por base a ideia de que esse conceito invoca uma série de posicionamentos e asserções que envolvem outros pressupostos, como o de cultura e identidade. Pretende-se apontar esse conceito como um campo complexo e que, no caso dos indígenas, envolve um forte sentido de alteridade expressada pela forma como eles se utilizam do recurso audiovisual ao abordar suas narrativas tradicionais - nesse caso, a Lenda da Cobra Grande - desenvolvendo uma expressão de voz síntese da historicidade dos Mbya-Guarani e, a partir desta, a síntese da historicidade dos Mbya-Guarani. Outro ponto também importante é o sentido do termo representação que, veiculado pelo suporte audiovisual, evidencia modos de vida e as concepções políticas e culturais da comunidade descrita. Nesse caso, a voz e a imagem assumiriam uma clara função comparativa ao se relacionarem no objeto fílmico possibilitando a construção representacional, reveladora de um traço subjetivo e coletivo da comunidade e dos sujeitos que se apropriam dos recursos audiovisuais.

\section{A dimensão oral da representação indígena: o caso do cinema}

Tomamos como corpus dessa pesquisa o projeto Vídeo nas Aldeias ${ }^{4}$ do qual o documentário aqui analisado é resultado. A produção aqui escolhida, constitui-se como um claro espaço de observação das tensões inerentes ao fenômeno da autorrepresentação, revelando-se como uma possibilidade de observarmos as formas como os recursos audiovisuais são incorporados pelas comunidades em questão. Além disso, o documentário evidencia as formas de inserção dos produtos culturais pelos índios dentro de contexto ligado à comunicação de massa e das mobilizações coletivas responsáveis por constituir novas formas de representação. Como a maioria dos produtos culturais

3. Dirigido por Germano Beñites, Ariel Duarte Ortega, Jorge Ramos Morinico, membros das duas comunidades Mbya-Guarani: "Aldeia verdadeira", em Porto Alegre (RS), e "Aldeia Alvorecer", no município de são Miguel das Missões (RS).

4. Criado em 1986, Vídeo nas Aldeias (VNA) é um projeto precursor na área de produção audiovisual indígena no Brasil. O objetivo do projeto foi, desde o início, apoiar as lutas dos povos indígenas para fortalecer suas identidades e seus patrimônios territoriais e culturais, por meio de recursos audiovisuais e de uma produção compartilhada com os povos indígenas com os quais o VNA trabalha. Para tanto, a técnica utilizada foi a de produção compartilhada do conhecimento: os indígenas trazem a ancestralidade, os ensinamentos da vida, da escuta, do sonho e os cineastas a técnica. A ideia de muitas das produções é de deixar o indígena com a câmera na mão, captando a partir de seu olhar em direção a um mundo em que o poder está em suas mãos, se autorrepresentando. Enfocaremos as questões de autorrepresentação na sequencia deste artigo. 
contemporâneos, o filme instaura um espaço de tensão tanto interna quanto externa, resultante da relação desse produto com seu público, e, também, do sistema que o abarca, seja por meio da distribuição ou da crítica - fundamentais para construção dos valores que legitimarão seu status como expressão cultural. É preciso, também, ressaltar no documentário a questão da autoria, que é singular quando contraposta à ideia de coletividade desenvolvida pelas produções que buscam constituir a representação de um grupo. Nesse caso, este seria muito mais do que o produto de uma construção próprio da autoria, a despeito da centralidade da figura do autor/diretor, já que a própria noção de autoria estaria circunscrita dentro de um sistema que abarca sua realização em produto cultural; que esboçaria uma espécie de autoria perceptível na relação desenvolvida entre os membros da comunidade e a ideia de uma representação coletiva Mbya-Guarani. De antemão, poder-se-ia perceber e apontar para o caráter representacional desenvolvido pelo sentido de autoria no cinema indígena. Também, a maneira como o filme se organiza, dentro de uma lógica da tensão dialética em suas estruturas, afeta o olhar daquele que, por alguma razão, se propõe a observar determinado objeto ou evento constituído dentro do sistema/organização social no qual se insere o documentário.

Escrever sobre um filme e, por conseguinte, analisá-lo, é apontar para seus engendramentos, decompô-lo e descrevê-lo em elementos menores dotados de autonomia, mas ainda ligados dentro do arranjo de sua micro e macroestrutura. O gesto analítico tem por objetivo o esclarecimento dos funcionamentos de um determinado filme pela busca de elementos que possibilitem a observação dentro da lógica desenvolvida, cabendo ao olhar de quem analisa reconstruir as relações de modo a perceber dentro desse arranjo as formas pelo qual o filme pode relacionar outras expressões e manifestações artísticas engendradas no âmbito da cultura. ${ }^{5}$ Sendo assim, compreender e ver um filme é também ouvi-lo, percebê-lo em seus elementos intrinsicamente constituídos em imagens, som e voz. Essa tríade compõe um importante conjunto representativo construído ao nível do produto fílmico. Se o filme é visto ele é também perceptível dentro de sua dimensão sonora. Portanto, sua constituição se deve muito mais a uma simples divisão entre som e imagem; sendo legitimado pelo caráter relacional que cada uma dessas instâncias exerce entre si e na outra. A voz ganharia, dessa forma, uma conotação bem específica, pois tensiona e revela elementos fundamentais como: enunciação, recepção, língua, discurso e

5. PENAFRIA, Manuela (2009), "Análise de Filmes - conceitos e metodologia (s)" in VI Congresso SOPCOM, abril. 
elementos narrativos como a verossimilhança e ambientação. ${ }^{6} \mathrm{O}$ som e a voz desenvolvidos são um atributo utilizado na construção do produto, carregando e revelando as caraterísticas que dão complexidade à produção cinematográfica; na sua relação com a cultura de massa e indústria cultural; mediante a uma linguagem, sintaxe e léxico que, na relação com as expressões populares e tradicionais, desenvolve-se diante da necessidade de construir uma ideia nova, por meio da reconfiguração do que seja velho, tradicional ou popular. ${ }^{7}$

Para Bill Nicholls, ${ }^{8}$ "cada documentário tem sua voz distinta" e, assim como a voz que fala, responde por uma ideia de estilo ou "natureza própria", conferindo ao filme uma espécie de "impressão digital". No livro Introdução ao documentário, o autor apresenta a voz como um critério para se definir o que ele chama de "tipos de documentário". 9 Nesse contexto, a voz pode ser entendida como um conjunto de elementos sonoros ou visuais que carrega uma expressividade, e que, de modo organizado e hierarquizado consegue, na arquitetura do filme, produzir um efeito característico próprio das realizações documentais. Ela seria, dessa forma, fundamental para o estudo do gênero, possibilitando perceber inclusive as diferenças entre cinema ficcional e documental. Vale ressaltar que, dentro da dimensão da voz e para além da voz tradicional constituída por elementos sonoros, poder-se-ia identificar uma outra dimensão ligada à escolha das imagens por meio do arranjo dos recursos visuais e sonoros imbricados no documentário. Essa voz estaria ligada à forma como o documentarista busca expressar uma determinada perspectiva, ao construir seu ponto de vista do mundo e do seu tempo.

\section{A voz no documentário: possibilidades de leitura da autorrepresentação, história e vida dos mbya-guarani}

Dado o exposto, poder-se-ia situar a voz no documentário tendo em vista a potencialidade que o recurso audiovisual oferece aos realizadores. Tal como um elemento base para a constituição do produto documental, a voz apresentase como um elemento de construção de autorrepresentação na medida em que estaria em consonância, de um modo geral, com o falar guarani. Construir uma autorrepresentação aproxima-se, fundamentalmente, do falar de si para o outro, apresentando, para o espaço onde o filme se expressa, a cultura de massa,

\footnotetext{
6. Todos esses são elementos de suma importância, entretanto, aqui, servem apenas de comprovação e exemplificação do corpus, não sendo nosso objetivo analisá-los em profundidade.

7. ADORNO, Theodor, (1994) A indústria cultural (reconsiderada). In: Theodor Adorno. Cohn, G(org). São Paulo: Editora Ática.

8. NICHOLS, Bill, (2005: 135) Introdução ao documentário, São Paulo: Editora Papiros.

9. Idem.
} 
os sujeitos portadores de um discurso inerente a histórias dos Mbya-Guarani. Aponta-se, dessa forma, para a relação entre voz e o documentário como uma ação comparativa que une sujeitos opostos; mas, ainda assim, ligados dentro do processo de construção subjetiva e dialógica, definida no espaço da cultura de massa.

O documentário Mokoi Tekoá Petei Jeguatá: duas aldeias, uma caminhada começa com uma apresentação dos aspectos que marcam a ideia de autorrepresentação. Para compreender esse conceito nos apoiamos nas contribuições de Gonçalves e Head que afirmam a ideia de que tal noção surge "como um modo legítimo de apresentar uma autoimagem, sobre si mesmo e sobre o mundo, que evidencia um ponto de vista particular, aquele do objeto clássico da Antropologia que agora se vê na condição de sujeito produtor de um discurso sobre si próprio". ${ }^{10}$ Constrói-se, dessa maneira, uma busca pelo papel determinante dos índios Mbya-Guarani como construtores e defensores de suas narrativas.

Nesse aspecto, a imagem do jovem que detém a câmara e a desloca na comunidade, como um personagem da tribo, é fundamental. Os planos são construídos, em sua maioria, como o recurso da câmera na mão. Os movimentos orgânicos da câmera parecem ressaltar o caráter representativo, ao reforçar a extensão do local e do espaço como interação de quem filma, reveladora dos aspectos característicos da tribo que ganha força, tendo por base os atributos do povo em consonância com o seu espaço.

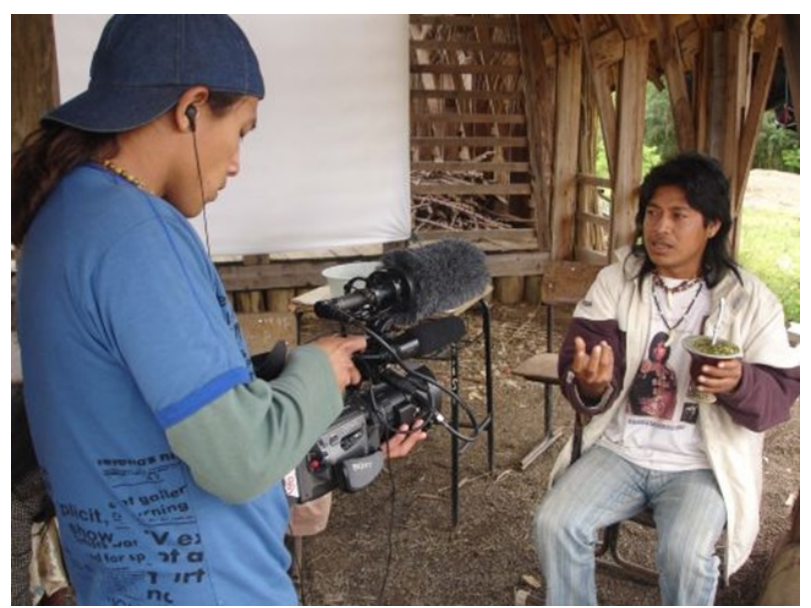

Figura 01. Mediação pela câmera

10. ALMEIDA, Francieli Lisboa de, (2013). Um índio com uma câmera: as autorepresentações indígenas através do vídeo - Campinas, SP : [s.n.]. (Dissertação de Mestrado defendida em Campinas). 
Narrado pelos índios guaranis, em sua própria língua, a construção do discurso fílmico tem, nesse aspecto, um ponto marcante ao evidenciar um caráter representativo da própria linguagem. Utilizando-se de recursos como entrevistas, que na sua maioria ocorrem de forma espontânea enquanto os índios estão no seu oficio e trabalho, a captação do áudio obedece a lógica do processo de obtenção das imagens utilizadas pela direção em constante diálogo com as características espaciais das comunidades representadas. Esse aspecto é importante por ser um dos pontos objetivados pelo documentário na construção de um discurso e posicionamento frente ao processo histórico que situou os indígenas em uma condição de marginalidade espacial, social e econômica.

Nessa lógica, o documentário deve ser observado como uma possibilidade de reposicionamento dos indígenas diante das narrativas privilegiadas. O estranhamento de alguns planos, bem como da angulação empregada e dos cortes envolvidos na composição das sequências fílmicas, reforça o caráter do olhar desenvolvido pelo documentário. A ausência de certos protocolos que, em outros documentários existiriam como norma, neste aparece como um recurso de determinação da especificidade da autorrepresentação.

Aponta-se, nesse caso, o uso recorrente de contre-plongée, ${ }^{11}$ evidenciando uma forma própria de ocupar e relacionar-se com o espaço. O enquadramento do filme parece seguir a regra de melhor explorar o objeto, ou seja, as duas aldeias, tendo como recursos principais o uso do plano médio e da câmera na mão. Chama atenção o uso do zoom como uma forma que diferenciaria o filme de outras produções assentadas em protocolos vigentes. O papel do zoom é interessante, pois reforçaria o caráter de autorrepresentação que entra no filme como um elemento fundamental para a construção e legitimação da imagem documental. Outro ponto interessante, ainda no posicionamento de câmera, é o papel que esta ocupa ao ser posicionada, quase sempre, na mesma posição do olho de quem filma. Esse posicionamento também é importante, pois denota o papel do documentário ao representar um olhar, desenvolvedor de uma forma de estar na comunidade. Tal posicionamento é reforçado pelo franco diálogo que se estabelece com quem está sendo filmado e quem filma, denominado por alguns da comunidade simplesmente pela alcunha de "câmera".

11. Posição da câmera que resulta na construção de um plano de baixo para cima em direção ao objeto filmado. Pode ser percebida no filme pelo posicionamento da câmera no chão, o que resulta em uma relação desigual ao objeto filmado. No filme, tal posicionamento também resultado em uma maior profundidade de campo que é explorado como forma de evidenciar constantemente o que está sendo filmado e o que não é filmado. 


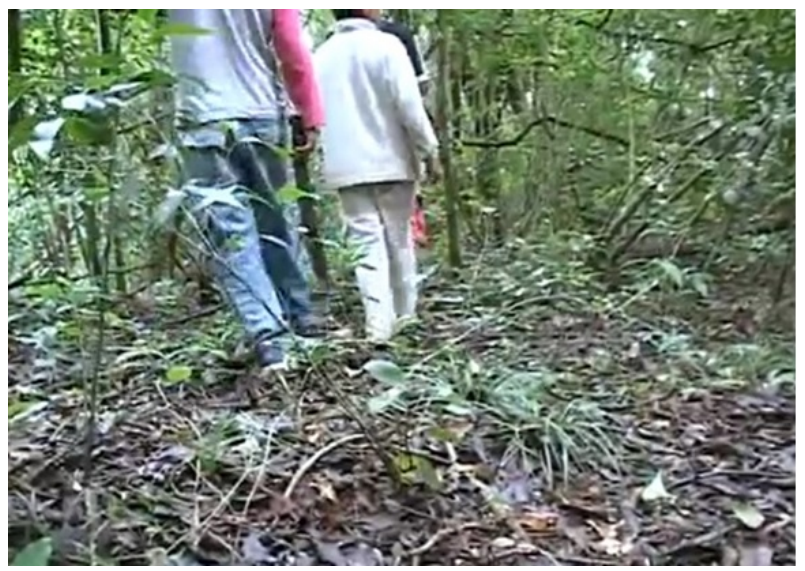

Figura 02. Câmera no chão

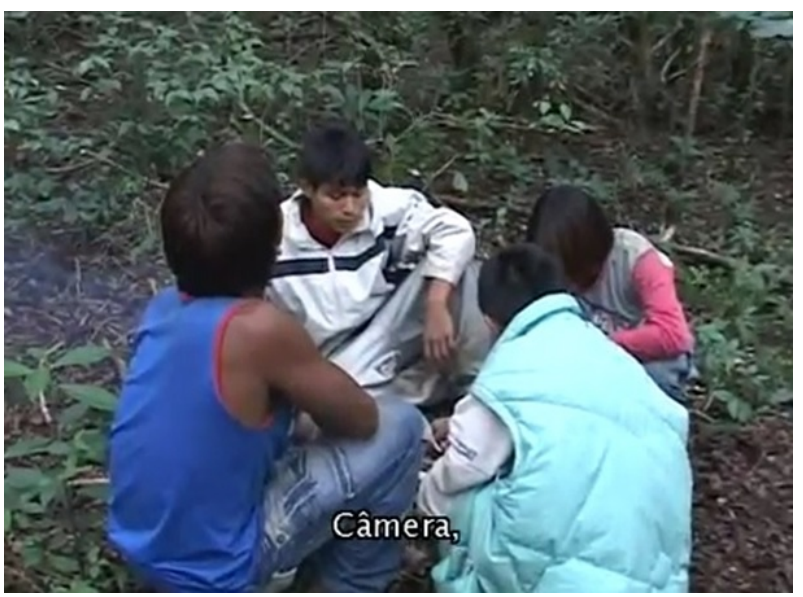

Figura 03. Diálogo com o "câmera"

A construção da imagem ocorre diante daquilo que Fernão Pessoa Ramos ${ }^{12}$ chamou de "transfiguração do real", em uma imagem possuidora de um traço específico, reveladora do gênero documental em detrimento do ficcional. A forma como o real é transfigurado para a imagem mediada pela câmera produz o efeito de uma imagem com caráter de testemunho em relação aos aspectos típicos dos índios Mbya-Guarani. Por meio da imagem seria possível perceber a forma como a câmera se desenvolve no espaço e no tempo ao repre-

12. RAMOS, Fernão Pessoa, (2001). O que é documentário? in Ramos, Fernão Pessoa e Catani, Afrânio (Orgs), Estudos de Cinema SOCINE 2000, Porto Alegre, Editora Sulina. 
sentar a realidade. A imagem documental, por conseguinte, seria reveladora de uma forma específica de mediar a realidade e da "circunstância de tomada" da câmera ${ }^{13}$ ao captar, registrar e de "estar" no mundo, marcas e traços do sujeito portador da câmera, mediação capaz de construir uma presença e uma ausência.

Existiria aqui um caráter fenomenológico e ético envolvido na imagem documental. Seria o documentário, então, a capacidade específica de construir imagens-câmera dotadas de um modo próprio de estar no mundo, "de significar uma forma de presença na circunstância de tomada". ${ }^{14}$ Se a circunstância de tomada se relaciona com o caráter constitutivo da imagem documental, envolvendo formas próprias de captar e estar no mundo, a dimensão discursiva do filme ganharia importância quando da montagem. Muito embora possamos apontar para a presença de uma enunciação ainda na construção das tomadas, seria na montagem o espaço onde o filme ganha um caráter discursivo, próximo, em certa medida, à ideia de encadeamento linguístico. Entretanto, apesar de o documentário envolver um modo próprio de encadeamento de imagem em uma montagem específica, seria sua capacidade de também produzir imagens contundentes, de "transfigurar a presença em imagem", ${ }^{15}$ um traço importante para a definição da imagem documental.

À vista disso, a tônica do documentário estará expressa em um dos registros de vídeo: "Para falar por nós próprios", o que evidencia na reprodução documental a possibilidade de construção de uma enunciação por parte dos Mbya-Guaranis. Nas duas localidades o papel das narrativas tradicionais Guaranis são elementos substanciais na construção do realismo no filme. As nar-

13. "A circunstância de tomada, para sermos mais específicos, é algo que conforma a imagem-câmera de um modo singular no universo das imagens. Por circunstância da tomada entendemos o conjunto de ações ou situações que cercam e dão forma ao momento que a câmera capta o que lhe é exterior, ou, em outras palavras, que o mundo deixa sua marca, seu índice de, no suporte de câmera ajustada para tal". RAMOS, Fernão Pessoa (2001: 8), O que é documentário? In: Ramos, Fernão Pessoa e Catani, Afrânio (orgs), Estudos de Cinema SOCINE 2000, Porto Alegre, Editora Sulina.

14. "O cinema não ficcional é voltado para o instante da tomada, para o transcorrer da duração na tomada e para a maneira própria que este transcorrer tem de se constituir em presente, que se sucede na forma do acontecer". Idem, pp.8-9.

15. Um dos aspectos fundamentais da imagem documental para Fernão Pessoa Ramos é a relação que a imagem documentário desenvolve ao relacionar a presença intermediada pela câmera em uma imagem dotada de sentido, transferindo para a imagem uma presença, capaz de ser percebida por meio da construção de imagens que se relacionem de alguma maneira com o modo como essas imagens foram tomadas, sua circunstância de tomada. A imagem documental seria assim uma articulação entre as características próprias do espaço e do tempo onde se daria a mediação da câmera, e capacidade do documentarista em transferir para a imagem, pela intermediação da câmera, as características desse espaço onde se dá a captação. Dessa forma, o documentário tem na tomada, na forma como essa ocorre, uma característica que a distingue substancialmente dos protocolos de registros comuns ao gênero ficcional. RAMOS, Fernão Pessoa, (2001) O que é documentário? In: Ramos, Fernão Pessoa e Catani, Afrânio (Orgs), Estudos de Cinema SOCINE 2000, Porto Alegre, Editora Sulina. 
rativas de origem cosmogônicas são apresentadas pelas vozes testemunhadas pelo olhar mediado pela câmera, apresentado aos demais da aldeia, relatado pelos índios mais velhos. O papel dessas narrativas desenvolve-se tendo por base o sentido do espaço, sobretudo pela propriedade que a natureza adquire na sua relação com o ser humano. Na maioria das representações indígenas, de forma abundante e orgânica, a natureza é trabalhada no documentário pela sua forma mais precária, resultado do processo de desfazimento do índio, pela desqualificação e empobrecimento do seu espaço. É diante da dificuldade do trato com a terra que o índio passa a se relacionar com o espaço urbano, com a finalidade de vender utensílios e produtos decorativos, como cestos, animais em madeira, arcos e flechas, objetos que aproximam e separam aldeia da cidade.

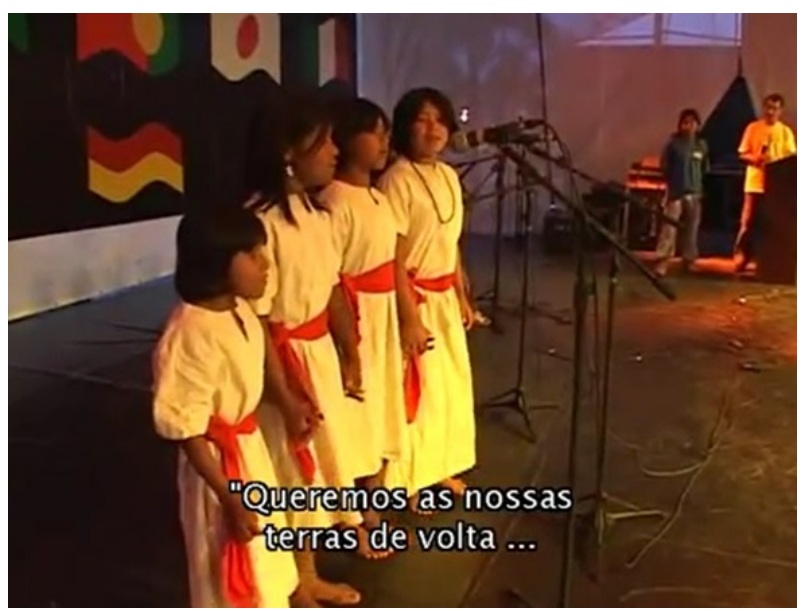

Figura 04. Apresentação dos Mbya-Guaranis na cidade.

É aqui que um interessante diálogo se estabelece entre os brancos e os índios, diálogo esse definido pelo contato possibilitado pelos produtos artesanais fabricados pelos indígenas. Tal contato culminará com aquilo que é, talvez, um dos pontos altos do documentário: o encontro entre os membros da aldeia e os brancos, turistas que visitam constantemente as ruínas dos Sete Povos das Missões, redução que no sec. XVII foi o palco da dramática expulsão jesuítica e que influenciaria para sempre os contornos e o papel da nação guarani no contexto colonial e na sua relação com a nação brasileira ainda em processo de formação. ${ }^{16}$

16. Aos conflitos surgidos dentro o período de 1750-1756, dá-se o nome de Guerra Guaranítica, e corresponde a uma série de conflitos que opuseram os índios guaranis e as tropas espanholas e portuguesas no sul do Brasil, em virtude da assinatura do Tratado de Madrid, assinado por Portugal e Espanha, no dia 13 de janeiro de 1752 . O respectivo tratado obrigava aos 
Assim, como as reduções jesuíticas de outrora, responsáveis pela construção do solo colonial e pela adaptação dos indígenas a um modo de vida reduzido aos limites estabelecidos dentro do processo colonial, o espaço atual, delimitado pela aldeia, responde por um isolamento contemporâneo, embasado em estereótipos perceptíveis em afirmações como: "ser índio é viver somente nas aldeias", ou "índio deve usar roupas de índios", ou ainda "o índio deve falar somente seu idioma". É diante da ideia de defesa dos modos de vida e da cultura dos Mbya-Guarani que a narrativa da Cobra Grande, mediada pelo aparato tecnológico de apreensão de sons e imagens, ganha uma importante dimensão, ao possibilitar uma releitura da história dos índios e criando meios e intercâmbios para se repensar o papel desses na cultura contemporânea.

Feitas tais considerações, nosso objetivo é enfatizar, na subseção seguinte, como a Lenda da Cobra Grande compõe uma poética que opera uma lógica que articula corpo e voz por meio da performance. Para isso, buscaremos examinar como, nas entrelinhas da história contada, se constituem múltiplos significados que atualizam elementos da tradição narrativa, tais como: tempo, espaço e enredo. E, ainda, como estes últimos, performatizados ao nível da câmera, instauram um posicionamento político frente aos discursos hegemônicos de dominação.

\section{A dinâmica narrativa}

Nessa perspectiva, faz-se necessário evidenciar a potencialidade da oralidade no documentário como uma forma de se observar o papel da voz tradicional presente no narrador que conta a Lenda da Cobra Grande. ${ }^{17}$ Na medida em que desenvolve sua narrativa, tal voz faz uso de uma série de mecanismos e técnicas que são apreendidos e incorporados ao longo de sua vida; saberes ancestrais passados de geração a geração. Ao se pensar num documentário que

índios guaranis da região dos Sete Povos das Missões a deixarem suas terras no Rio Grande do Sul, obrigando-os a se transferirem para o outro lado do rio Uruguai. A querela estendeu-se, tendo em vista o direito de escravizar os índios, permitida pela coroa portuguesa, enquanto que esse era desaprovado pelo Império Espanhol, já que eram os índios considerados como súditos do Rei da Espanha. Em 1759 a Companhia de Jesus foi expulsa de terras portuguesas e, em 1767, da Espanha. Os eventos aqui citados foram fundamentais para que no ano de $1801 \mathrm{o} \mathrm{im-}$ pério português tivesse por completo a supremacia na região, abrindo caminho para constituição do estado do Rio Grande do sul.

17. "A Lenda da Cobra Grande, surgiu com o término das missões jesuíticas no Rio Grande do Sul. Atravessou o tempo na boca do povo dizendo que na guerra contra os invasores os índios, comandados por um grande guerreiro Sepé Tiaraju, lutaram bravamente mas acabaram sendo vencidos. A maior parte deles foi dizimada ou feita prisioneira. Na Missão de São Miguel ficaram apenas os velhos, mulheres e crianças, que tão logo tivessem alguma serventia eram levados por estrangeiros como escravos. Por consequência, o mato foi crescendo e avançando invadindo a Missão. Com o mato veio a Cobra Grande, que subiu as escadas do templo e se alojou na torre da igreja. Quando sentia fome, enroscada nas cordas que pendiam do alto, atirava-se a badalar...badalar"... ( in: http://cbtij.org.br/mboiguacu-lenda-da-cobra-grande/) 
se propõe a ser o registro de uma ancestralidade para além do que estamos aqui enfatizando, bem como todos os demais presentes na série Vídeo nas Aldeias, o vídeo representa a possibilidade de fixação não só de uma performance, mas, no caso dos indígenas, de toda uma cultura que foi massacrada pelos colonizadores, a ponto de ser quase que completamente apagada. O documentário é, portanto, um objeto de luta pelo não (total) apagamento, pelo rememorar, e que tem em seu processo criativo toda uma organização textual dinâmica, interativa, que implica jogo de transformações que se dá entre o discurso anunciado (a luta pela terra, pela identidade, pela autorrepresentação) e a enunciação (o vídeo em si); o entrecruzamento do tempo e do espaço em suas possibilidades performativas.

Aponta-se, nesse aspecto, para a importância dos processos enunciativos e das estratégias desenvolvidas pelos indígenas na sua relação com os recursos audiovisuais. As enunciações constituiriam, dessa maneira, um meio de observação das estratégias de apropriação dos recursos expressivos por parte dos sujeitos do discurso diante daquilo que Benveniste (1989) ${ }^{18}$ chamaria de semantização da língua. ${ }^{19}$ Seria no plano semântico que estariam tensionados os processos de constituição de sentidos oriundos, tanto da comunidade por meios da operacionalização da linguagem verbal presentes nas narrativas tradicionais, e da linguagem audiovisual, vinculada a uma ideia de enunciação desenvolvida ao nível dos recursos audiovisuais. Lançar um olhar para as especificidades de apropriação desses recursos pelos indígenas é observarmos como esses povos desenvolvem sentidos ao constituir uma narrativa documental em diálogo com suas tradições e História. Dessa maneira, a narrativa possui implicações e nelas há tendências que se incorporam a esse novo suporte de circulação presente no documentário. No entanto, é preciso frisar o tributo à transmissão oral dos conhecimentos armazenados na memória humana e a utilização desta, de forma revigorada no documentário, já que o passado nela se reapresentaria através dos processos de criação, adaptação e circulação:

Depois os nossos parentes foram levados, pelos Bandeirantes, como chamam eles agora.

Eles nos levavam, quando não nos matavam faziam a gente trabalhar sem comer. Se a gente adoecia, eles matavam, e nem enterravam.

Foi isso que eles fizeram com os que sobreviveram.

Mas uma pessoa escapou, e eles não conseguiram pegar.

18. BENVENISTE, Émile (1989). Problemas de Linguística Geral II. Campinas, pontes.

19. Aline Juchem, ao explicar em seu artigo "Saussure, Benveniste e o objeto da linguística", explica, a partir de Flores (2008: 37) que a semantização da língua está na sua passagem para discurso pela transformação individual que dela se faz, conceituando esse processo como "relação constitutiva língua-discurso". Nosso objetivo, aqui, ao trazer a enunciação, é o de nos apropriarmos do conceito naquilo em que ele pode dialogar com o cinema. Não há pretensão, de nossa parte, de uma aprofundada análise nos termos exigidos pelas teorias da enunciação. 
Quando não se ouvia mais nada por aqui, ele voltou pra cá. E ficou sentado no pátio com algumas crianças.

- Foi aí que apareceu a cobra grande, né?

Ah, ela estava lá em cima.

Naquela época o sino não tinha caído ainda. Estava tudo tomado de mato, como na foto lá do museu.

Era tarde, era quase escuro, quando um dos sinos tocou. Então ele pensou que ainda tinha gente lá. E entrou.

Lá dentro uma das crianças desapareceu.

- A criança que ela levou?

Era a cobra grande que estava tocando o sino com o rabo. Foi ela que comeu a criança.

Mas quando Nosso Deus Tupã vê algo errado acontecendo, Ele se transforma em tempestade.

Então um raio explodiu o sino, e fez a cobra cair.

O sangue e a gordura da cobra mancharam as paredes.

A gordura da cobra se misturou com sangue.

É aqui, olha as manchas lá.

Algumas vezes quando você olha, a gordura fica mais visível.

Quando o raio bateu, o sino que está no museu caiu.

Primeiro ele ficava aqui, antes dos brancos mexerem. ${ }^{20}$

Sendo assim, o narrador assume um tom político e questionador ao relatar com maestria a lenda. Ele se coloca como porta-voz do seu povo, definindo-se como autor e protagonista da sua história. Fala dos seus antepassados, porém incluindo sua descendência, ao mesmo tempo em que narra, revive sua memória, atualizando-a quando diz: Eles nos levavam, quando não nos matavam faziam a gente trabalhar sem comer. Se a gente adoecia, eles matavam, e nem enterravam. ${ }^{21}$ Ao mesmo tempo em que conta ele invoca as vozes silenciadas e dizimadas de seu povo, os Mbya-Guaranis, fazendo ressurgir, desta maneira, uma outra história que questiona um lugar de fala, usurpado dentro do conjunto social dominante. Ou seja, por meio da lenda ele desconstrói discursos hegemônicos e, assim como pela sedução das palavras, faz fluir os sons reveladores dos modos de vida e das tradições: Mas uma pessoa escapou, e eles não conseguiram pegar. Quando não se ouvia mais nada por aqui, ele voltou pra cá. E ficou sentado no pátio com algumas crianças. ${ }^{22}$ Por esta perspectiva, se a história oficial tenta apagar as vozes dos índios deixando-as à margem, é por meio da lenda, pelo contar que o povo Guarani reinventa seu papel no con-

20. Mokoi tekoá petei jeguatá. Documentário, drama. Direção: Germano Beñites, Ariel Duarte Ortega, Jorge Ramos Morinico. Tecnologia digital. Colorido, estéreo. 63 min. Brasil, 2008. (VÍDEOS NAS ALDEIAS, 2007/2008, 2m 51s).

21. Idem.

22. Idem. 
temporâneo, ao remontar a tradição, buscando trazer para o centro os dilemas presentes em sua história.

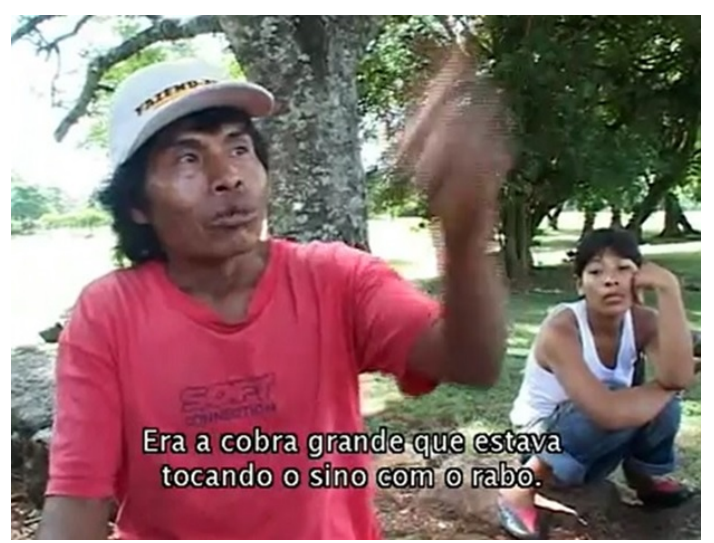

Figura 05. Narrador
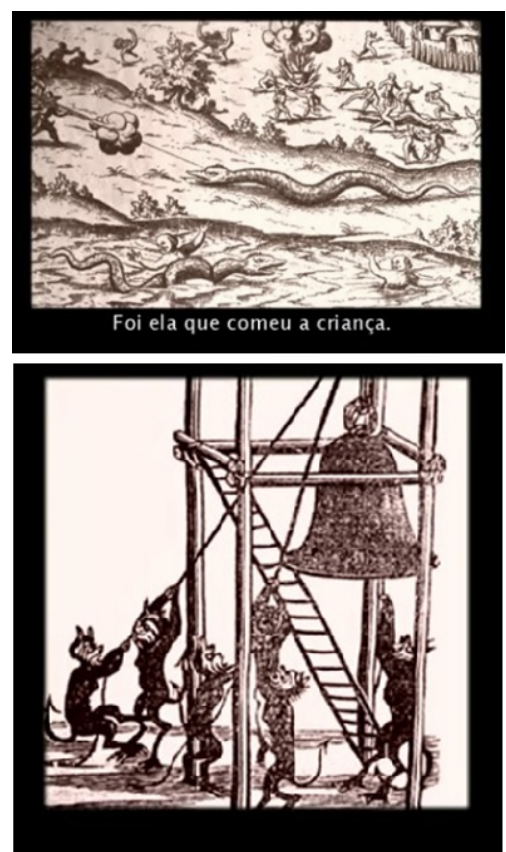

Figuras 06 e 07. Inserções sobre a narrativa 
Pode-se dizer que o enfoque documental da lenda, carrega a vocalidade, como afirma Zumthor, ${ }^{23}$ porque em suas origens há uma criação coletiva e oral das vozes do passado, vozes estas que são trazidas para a contemporaneidade. "A comunicação poética passa de um registro para o outro produzindo uma mutação radical. Ela continua virtual, escondida no texto como uma riqueza tanto mais maravilhosa porque irrealizada". ${ }^{24}$ As mediações que circulam os dias atuais são carregadas de novos artifícios, modernidades, adaptações. Contudo, a força das histórias contadas se sustenta na memória vocalizada, traço este que não se perde mesmo ao longo dos séculos. Tal fato compõe um processo germinal: o movimento de transferência oferecido ao público atual, através da captação audiovisual, num compasso entre oralidade, constituída pela enunciação dos sujeitos, e oralidade mediatizada, por parte do documentário.

- Foi aí que apareceu a cobra grande, né?

Ah, ela estava lá encima.

Naquela época o sino não tinha caído ainda.

Estava tudo tomado de mato, como na foto lá do museu ${ }^{25}$.

O documentário, ao abordar a lenda, volta-se para a potencialidade da voz Mbya-Guarani. Para isso, enquanto é feito o relato as cenas são reapresentadas em desenhos fotografados. O próprio narrador testifica a sua narrativa e faz referência a esse mecanismo imagético incorporando-o à sua versão: $E s$ tava tudo tomado de mato, como na foto lá do museu. ${ }^{26}$ Aqui, a produção audiovisual se deixa conduzir pelo ato narrativo. A análise da lenda aliada ao mecanismo tecnológico promove um diálogo que confirma a hipótese de um entrelaçamento que contempla formas de expressão distintas. Ainda sobre a representação documental da narrativa é possível escutar uma voz que se manifesta em performance graças a riqueza da tradição que se deixa transmutar em outros meios, nesse caso pela realidade transfigurada em imagem documental.

Para que uma produção cultural permaneça segura em si, muitas vezes ela pode absorver elementos do domínio da cultura de massa, o que potencializa suas produções devido a sua hibridez característica. Em algumas culturas essas incorporações são associadas às tradições e, dessa forma, contribuem para sua

23. Zumthor (1993:21) descreve vocalidade como a historicidade de uma voz: seu uso. Uma longa tradição de pensamento, é verdade, considera e valoriza a voz como portadora da linguagem, já que na voz e pela voz se articulam as sonoridades significantes. VER: A LETRA E A VOZ: A "LITERATURA" MEDIEVAL.

24. ZUMTHOR, Paul, (2010:39). Introdução à poesia oral. Trad. Jerusa Pires Ferreira, Maria Lúcia Diniz Pochat, Maria Inês de Almeida. - Belo Horizonte: Editora UFMG.

25. MOKOI TEKOÁ PETEI JEGUATÁ. Documentário, drama. Direção: Germano Beñites, Ariel Duarte Ortega, Jorge Ramos Morinico. Tecnologia digital. Colorido, estéreo. $63 \mathrm{~min}$. Brasil, 2008. (VÍDEOS NAS ALDEIAS, 2007/2008, 2m 51s).

26. Idem. 
permanência e realizações. Zumthor ${ }^{27}$ explica que uma narrativa deverá ser examinada sobre suas constantes e mutáveis relações das quais resultam o encadeamento de seus elementos e a produção de infindáveis sentidos. Destacase "pela ausência de artifícios refreando as reações afetivas; a predominância da palavra em ato sobre a descrição; os jogos de eco e de repetição; o imediatismo das narrações, cujas formas complexas se constituem por acumulação; a impessoalidade, a intemporalidade". Essas são características que se apresentam na Lenda da Grande Cobra e que nos faz percebê-la como um texto oral que veicula grande carga expressiva, pois evidencia identidades culturais, discursivas e políticas.

Dessa forma, o texto oral focaliza-se em performance, "a arte poética consiste em assumir esta instantaneidade, em integrá-la na forma de seu discurso. Daí a necessidade de uma eloquência particular, de uma facilidade de dicção e de frase, de um poder de sugestão: de uma predominância geral dos ritmos". ${ }^{28}$ O ouvinte/espectador segue este encaminhamento ao assistir ao vídeo documentado. Nesta condição, não há possibilidade de retorno, desistência. A mensagem em performance atinge seu objetivo e o efeito desejado.

Tomando como referência o estudo desenvolvido pelo teórico Frederico Fernandes em seu livro intitulado $A$ voz e o sentido: poesia oral em sincronia ${ }^{29}$ dois conceitos podem ser analisados e incorporados para efetivo desenvolvimento de nossa análise: 1) Relato, "que constitui um feixe de histórias a que se somam acidentes, desilusões, aventuras, esperanças, saudades, engendra-se pelo exercício do olhar". Neste caso, o espectador guia-se pelo olhar do narrador, que vislumbra os acontecimentos e os readapta por meio da oralidade no documentário. Os relatos são documentos que reapresentam o passado, porém como uma possibilidade de se compreender o viver no presente; 2) Narrativa, "sendo constituída com base num passado próximo, o exercício mnemônico que a viabiliza não pressupõe a descrição do convencional, isto é, daquilo que já se apresenta assimilado no mundo percebido de quem articula". ${ }^{30}$ Relocando o conceito de narrativa desenvolvida pelo autor acima citado como um deslocamento espacial e temporal que se insere na descoberta pelo que é "o novo", o "desconhecido", é possível analisar a lenda por esta perspectiva, por meio do "novo" e do "desconhecido" que se instauram em meio às diversas

27. ZUMTHOR, Paul, (2010:138). Introdução à poesia oral. Trad. Jerusa Pires Ferreira, Maria Lúcia Diniz Pochat, Maria Inês de Almeida. - Belo Horizonte: Editora UFMG.

28. ZUMTHOR, Paul, (2010:139). Introdução à poesia oral. Trad. Jerusa Pires Ferreira, Maria Lúcia Diniz Pochat, Maria Inês de Almeida. - Belo Horizonte: Editora UFMG.

29. FERNANDES, Frederico Augusto Garcia, (2007) A voz e o Sentido: poesia em sincronia. São Paulo: Editora UNESP.

30. Idem, p. 66. 
reinterpretações do espectador/ouvinte, que também compartilha desta curiosidade pelo inusitado que se revela na narração.

Por conseguinte, a lenda é marcada por pensamentos inconclusos, mas não menos significantes. No documentário é possível perceber a presença marcante dos gestos que assinalam uma comunicação presentificada e a ausência de divagações psicológicas, além claro, da audiência dos seus pares que observam, atentos, o desenrolar narrativo. O fator marcante da poesia oral é o tempo e espaço em que ela é comunicada. ${ }^{31} \mathrm{O}$ autor explica que a comunicação não está no vazio do tempo, mas encontra-se em um presente que sofre interferência de um passado para, dessa forma, projetar o futuro. É um encontro cíclico que nunca finda. Ele ainda discute sobre a principal diferença entre a comunicação espacial, aquela movida pelo delimitar de um lugar, objeto, códigos, canais e pessoas, da poesia oral, a qual se apresenta pelo contato direto com o receptor e o retorno a memória oral, possibilitando que se estabeleça um evento comunicacional entre os pares que se fazem presentes em performance.

Outro fator preponderante que se deixa sobressair na lenda é o aspecto religioso, bem demarcado em seu espaço cultural, do qual podemos extrair elementos que se encaixam perfeitamente ao mundo mítico das tradições indígenas. Mas quando Nosso Deus Tupã vê algo errado acontecendo, Ele se transforma em tempestade. Então um raio explodiu o sino, e fez a cobra cair. ${ }^{32}$ Assim, o autor materializa, por intercâmbio do visual, um mundo imaginário coberto de costumes, magia e fé. Ele se apropria de inúmeras combinações e alcança, desta forma, "um suporte cultural preexiste". ${ }^{33}$

Interessante perceber que o narrador percorre sua própria cultura para "desenhar" a lenda e reapresentá-la perante a câmera. Traça em sua composição um movimento de ir e vir que evidencia um repertório composto por pontos de vista e ideologias. Nesse sentido, o documentário está a serviço de comunicar e registrar as realidades vividas pelos membros da comunidade, mas também por outras pessoas, sejam do presente ou do passado. Assim, a lenda ganha notoriedade e se faz presente, não apenas em seu contexto de produção, mas de toda uma população que possa ter acesso ao vídeo, hoje disponível em canais de YouTube e/ou distribuída em DVDs.

Nesse contexto, o público tem a possibilidade de compreender formas variadas da representação da cultura indígena Guarani que se faz e refaz por meio

31. Idem, p. 35.

32. MOKOI TEKOÁ PETEI JEGUATÁ. Documentário, drama. Direção: Germano Beñites, Ariel Duarte Ortega, Jorge Ramos Morinico. Tecnologia digital. Colorido, estéreo. $63 \mathrm{~min}$. Brasil, 2008. (VÍDEOS NAS ALDEIAS, 2007/2008, 2m 51s).

33. FERNANDES, Frederico Augusto Garcia(2007: 69). A voz e o Sentido: poesia em sincronia. São Paulo: Editora UNESP. 
da lógica dos ritos tradicionais, a crença em seres míticos, a luta por um mundo melhor, neste caso, a necessidade de minimizar as diferenças decorrentes do processo histórico de dominação e desigualdade. O público, a partir desse projeto, vislumbra outra história, novas interpretações e, ao mesmo tempo, questiona a homogeneidade perversa do discurso oficial.

A todo instante da narrativa o realizador indígena está presente, mediando a relação de sua cultura com o exterior. Como alguém que constitui um elo entre dois mundos, os Mbya-Guaranis trazem para o plano da representação documental aspectos de sua cultura, manipulando as ferramentas audiovisuais com o intuito de inserir-se nos espaços da comunicação de massa. No gesto de reafirmação de sua natureza, ao dialogar com o campo e o antecampo, estaria subjacente um certo caráter afirmativo do poder dos índios como porta-vozes de um processo de esquecimento vivido na história, reposicionando-os frente à cultura de massa. É diante do processo de constituir vozes esquecidas que o filme se desenvolve. Dessa forma, as lendas e os falares dos índios estão completamente ligados ao processo de feitura do filme. Interessante notar como as vozes têm um papel preponderante ao revelar os conjuntos das narrativas próprias da tradição em contato com as reivindicações Mbya-Guarani.

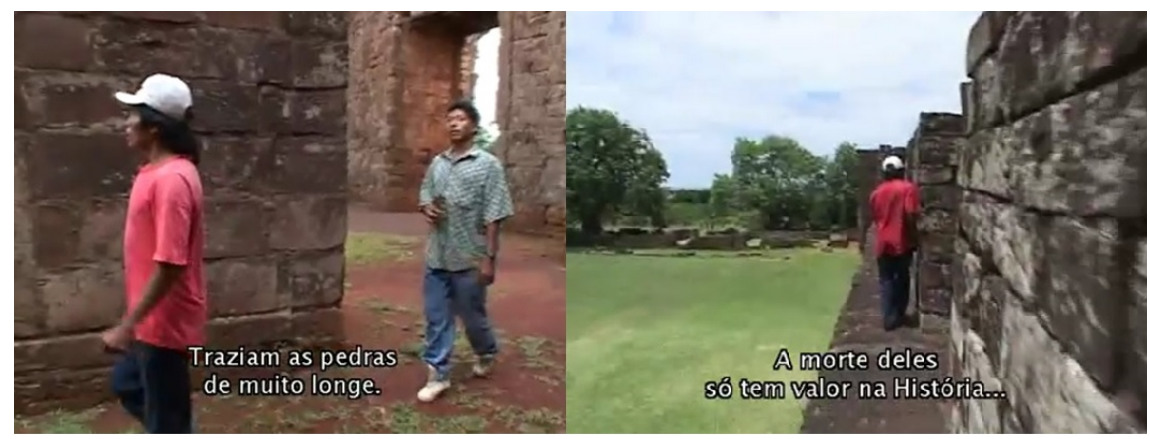

Figuras 08 e 09. Uma voz histórica

Nesse caso, como apresentado por Brasil (2013), ${ }^{34}$ a relação de reflexividade entre o campo e o antecampo poderia também ser perceptível na relação estabelecida pelas narrativas tradicionais Guaranis, em especial a Lenda da Cobra Grande, ao se pensar a potencialidade do cinema em trazer, para o campo, o espaço diegético, as histórias que comporiam o antecampo. O caráter dialógico é, inclusive, preservado na dimensão do diálogo, já que a narrativa é apresentada tendo em vista o diálogo desenvolvido pelos dois índios.

34. BRASIL, André, (2013: 245 - 267) Mise-en-abyme da cultura: a exposição do "antecampo” em Piõnhitsi e Mokoi Tekoá Petei Jeguatá. Revista Significações. São Paulo, n. 40. 
Destarte, compreender a lenda como um dispositivo operante que diverte, ensina e transmite, é entender que este pode nos transportar para além de uma versão puramente narrativa.

\section{Do diálogo campo/antecampo no documentário: algumas conclusões so- bre a voz Mbya-guarani}

A partir de nossas análises, pode-se perceber que a narrativa tradicional desenvolvida pelo documentário Mokoi Tekoá Petei Jeguatá: duas aldeias, uma caminhada ${ }^{35}$ possibilita lançar um olhar para as formas como os próprios indígenas desenvolvem e potencializam suas vozes. O documentário, por conseguinte, se constitui na dualidade das culturas, na medida em que os indígenas reafirmam modos próprios, performatizados na cultura do outro, possibilitam observar, de forma crítica, a cultura branca. Nesse espectro, além de uma abordagem interativa, intercultural, acerca da autorrepresentação, outras questões estariam evidenciadas no documentário, questões que revelariam os traços específicos que marcariam a negociação entre a relação das imagens, inerentes à cultura Mbya-Guarani e a cultura de massa. Tais apontamentos são perceptíveis nas construções específicas dessas comunidades nas suas formas de constituição de imagens e no registro dos seus aspectos, vistos, por si e pelo demais, como tradicionais. Estaria evidenciada nessa construção a própria fragilidade do uso do termo tradicional expresso em sua maioria pela identificação dos traços, por parte de quem observa o filme, estabelecido no critério de negociação intercultural.

Assim, é importante destacar que coexistiriam, no documentário, os elementos dialógicos estabelecidos entre as culturas envolvidas no processo histórico vivido pelos índios. É nesse aspecto que se deve observar a característica do diálogo desenvolvido no documentário que não parece perder de vista o elemento relacional, consubstanciado na relação direta entre o mundo indígena e o não-indígena. A dimensão dialógica do documentário é perceptível não somente nos diálogos desenvolvidos pelo filme dentro do espaço diegético, mas também na presença de toda uma cadeia relacional presente no antecampo. ${ }^{36}$

35. MOKOI TEKOÁ PETEI JEGUATÁ (2008). Documentário, drama. Direção: Germano Beñites, Ariel Duarte Ortega, Jorge Ramos Morinico. Tecnologia digital. Colorido, estéreo. 63 min. Brasil, 2008.

36. Como nota Brasil (2013), o uso do antecampo estaria presente em inúmeros filmes indígenas. A "exposição do antecampo" seria um traço recorrente do cinema indígena. Essa estratégia expositiva, possibilitaria aos realizadores se implicarem na composição da cena, coexistindo na mediação cinematográfica, uma ideia de reflexividade, perceptível na figura do realizador e o do membro da aldeia. "O antecampo é o lugar onde o realizador encena esse duplo intercambiável papel: dentro da cena, como parente e membro da comunidade; e fora da cena, como cineasta" (p. 266). BRASIL, André, Mise-en-abyme da cultura: a exposição do 
A exposição do antecampo, por seu lado, reforça um caráter de engajamento do filme dentro de uma realidade especifica. Nesse caso, o papel das vozes representadas pelo documentário tem um valor marcante ao expor o diálogo e a dimensão reflexiva das imagens. O franco diálogo estabelecido tem na mediação da câmera um ponto convergente, perceptível na concordância do olhar da "câmera", também falante da língua Guarani, uma câmera em conformidade com a historicidade e complexidade da vida Guarani.

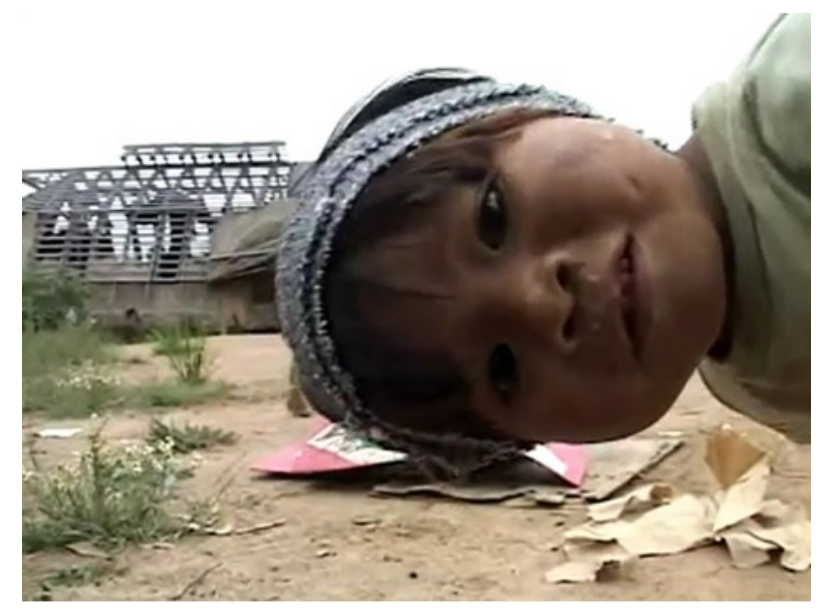

Figura 11. Um olhar para o antecampo

Nos dizeres do índio acerca da lenda estaria implícita uma outra forma de observar o surgimento das ruinas. A lenda da cobra grande, como uma explicação das origens históricas dos guaranis, recoloca as ruinas como um espaço próprio para a resistência dos Mbya-Guarani. A lenda surge como uma reafirmação perante o mundo já recontado pelas narrativas vigentes; tendo, agora, nas vozes dos indígenas, uma explicação que trouxesse a marca da exclusão e do empobrecimento das fontes naturais da vida dos índios. Narrativa e história se aproximam como forma de apontar o papel prevalente do extracampo no documentário. Nesse caso, o constante jogo campo e antecampo tem o papel de potencializar a narrativas como reafirmação dos atributos dos Mbya-Guaranis, reposicionando suas vozes não somente para o cinema, mas para as lutas e a perpetuação dos seus modos de vida.

"antecampo" em Piõnhitsi e Mokoi Tekoá Petei Jeguatá. Revista Significações. São Paulo. n. 40. 2013. pp. $245-267$. 


\section{Referências bibliográficas}

Adorno, T. (1994). A indústria cultural (reconsiderada). In T. Adorno \& G. Cohn (Org). São Paulo: Editora Ática.

Almeida, F.L. (2013). Um índio com uma câmera: as auto-representações indígenas através do vídeo. Campinas, SP : [s.n.]. (Dissertação de Mestrado defendida no Programa de Pós-Graduação em Antropologia na Universidade Estadual de Campinas Instituto de Filosofia e Ciências Humanas - UNICAMP.

Benveniste, É. (1989). Problemas de Linguística Geral II. Campinas: Pontes.

Brasil, A. (2013). Mise-en-abyme da cultura: a exposição do "antecampo" em Piõnhitsi e Mokoi Tekoá Petei Jeguatá. Revista Significações. São Paulo.

Franco, R.D. (2008). A voz: uma concepção fenomenológica. Dissertação de mestrado do Programa de Pós-Graduação em Música. Universidade Federal do Paraná, Curitiba.

Fernandes, F.A.G. (2007). A voz e o Sentido: poesia em sincronia. São Paulo: Editora UNESP.

Penafria, M. (2009). Análise de Filmes - conceitos e metodologia (s). VI Congresso SOPCOM.

Nichols, B. (2005). Introdução ao documentário. São Paulo: Papiros editoras.

Ramos, F.P. (2001). O que é documentário?. In F. P. Ramos \& A. Catani (orgs), Estudos de Cinema SOCINE 2000. Porto Alegre: Editora Sulina.

Zumthor, P. (2010). Introdução à poesia oral. Tradução: J. P. Ferreira, M. L. D. Pochat \& M. I. Almeida. Belo Horizonte: Editora UFMG.

Zumthor, P. (1993). A letra e a voz, A “literatura” medieval. São Paulo: Companhia das Letras.

\section{Filmografia}

Mokoi tekoá petei jeguatá (2008). de Germano Beñites, Ariel Duarte Ortega, Jorge Ramos Morinico. 